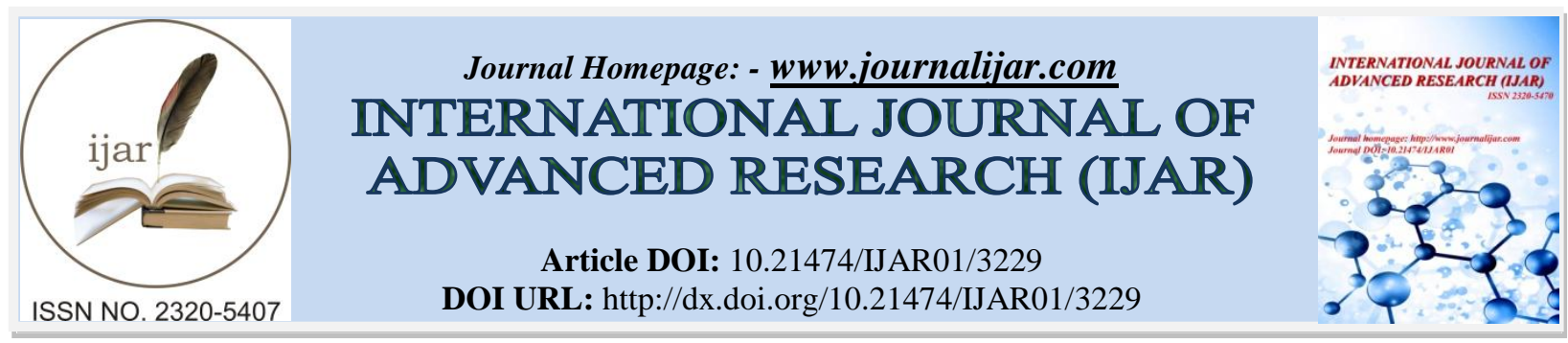

RESEARCH ARTICLE

\title{
HISTOPATHOLOGICAL STUDY OF TUBERCULAR ENDOMETIRTIS IN PATIENTS OF PULMONARY TUBERCULOSIS WITH CILINICAL CORRELATION IN A TERTIARY REFERRAL UNIT OF ODISHA.
}

\section{Dr. Nalini Prava Das ${ }^{1}$, Dr. Bandana Rath ${ }^{2}$, Dr Priyanka Das ${ }^{3}$, Dr. Sasmita Das ${ }^{4}$, Dr. Nina Mishra ${ }^{5}$ and Dr. Jyoti Pattnaik6.}

1. Asst Prof. Pulmonary Medicine.

2. Assoc. Prof. Pharmacology.

3. Pulmonary Medicine.

4. O \& G Specialist.

5. Asst. Prof. O \& G.

6. Prof. Pulmonary Medicine.

\section{Manuscript Info}

Manuscript History

Received: 09 December 2016

Final Accepted: 10 January 2017

Published: February 2017

Key words:-

Pulmonary Tuberculosis, Tubercular Endometritis, Histopathology, Z-N staining AFB .

\section{Abstract}

Background:-

After tuberculosis has been declared as Global emergency it has reawakened the interest of doctors. Genital Tuberculosis has been a subject of keen interest because it has impact on female infertility. Here this study aims at to study the Histo-pathological outcome of endometrial biopsy in diagnosed cases of Pulmonary Tuberculosis.

Methods:-

62 females Cases of diagnosed PTB of age Group 15-45 years having history of genital tuberculosis were enrolled in this study. The endometrial tissues of each patients collected and subjected to Histopathological examination and wherever required for bacteriological examination i.e. Z-N staining for AFB.

\section{Results:-}

Among 62 patients, highest incidence (59.68\%) belong to 21-30 years age group and presented with in $1^{\text {st }}$ year of development of PTB. Secondary amenorrhea, list of vaginal discharge and cervical erosion were observed in $24.19 \%$ and $25.81 \%$ of cases respectively, Eight (8) cases $(12.90 \%)$ had histological finding of chronic endometritis. Out of them Four (4) cases $(6.45 \%)$ were AFB positive on Z-N staining of endometrial tissue.

Conclusion:-

Endometrial tuberculosis though rare in pulmonary tuberculosis cases, bacteriological and histo-pathological examination of endometrial tissue should be done for early diagnosis and treatment.

Copy Right, IJAR, 2017,. All rights reserved.

\section{Introduction:-}

The World Health Organization in 1993 declared tuberculosis, a common infectious disease in the Indian subcontinent, as “a Global emergency”'. (Talib et al, 1993) India, the world's second most populous country, 
accounts for a quarter of the world's annual incidence of TB. Every year, around two million people develop TB in India and 300,000 die of TB. Over 15 million patients have been treated and three million cases were cured in last decade. (VK Arora et al 2017, MOHFW, Govt of India, 2017). Endometrial tuberculosis though rare in developed countries it is still common in developing and poor countries.(Khan Nawaz, 2005) It is almost secondary to a primary focus elsewhere in the body. Fallopian tubes are commonly the initial site of involvement and is affected mostly. (Nabamber, 2001) From primary site of tubercular infection it spreads to genital tract initially to the tubes and in most cases through the blood stream. (Kajal B Punyashetty, 2012) Female genital tuberculosis accounts to be 5-15\% of infertility cases among Indian women. (Kriplani et al 2017) In India, the incidence of genital tuberculosis in infertility has been reported in $19 \%$ cases and among them $41 \%$ have tubal cause. (Tripathy and Tripathy 2002 ) As genital tuberculosis has a tremendous impact on the reproductive health in our country, in present scenario it has been a subject of keen interest. Many studies have been undertaken in this context (Kemal Güngördük, 2007). With this background this study aimed to find out the histopathological features of endometrium of infertility cases associated with pulmonary tuberculosis, so that early diagnosis and treatment with anti-tubercular drugs may be helpful in patients of genital tuberculosis.

\section{Materials and Methods:-}

This observational study was carried out from 2013 to 2016 in the department of Pulmonary Medicine in collaboration with department of Obstetrics and Gynecology at a tertiary care hospital of Odisha. The ethical clearance was obtained from Institutional Ethics Committee. Written informed consent form was obtained from all the willing participants fulfilling the inclusion criteria. (Jai B Sharma et al, 2014)

As per the inclusion criteria, 62 females in the reproductive age group (15-45 years) diagnosed as pulmonary tuberculosis (RNTCP, 2012) along with some gynecological problems who were on with or without anti- tubercular treatment were enrolled. The gynecological problems included amenorrhoea, menorrhagia, dysmenorrhoea and other menstrual irregularities. The females with primary or secondary infertility cohabiting with their husbands were also included. (Kriplani et al 2017) The women with extrapulmonary tuerculosis and genital infection with other non tubercular infection were excluded from the present study.

A detailed history was undertaken and general physical examination; respiratory system as well as pelvic examination was carried out on all subjects. Pervaginal examination was performed on all women to observe any abnormality in vagina, cervix and uterus or adnexal mass if any. In all selected subjects the endometrial samples were taken for microscopic examination for AFB and histopathological examinaton. The patients were kept on antitubercular treatment under RNTCP.

The basic characteristics, clinical findings, radiological observations and laboratory data were noted in a case record form. The data were analysed using MS Excel.

\section{Results:-}

Among total 62 women with pulmonary tuberculosis in the study sample, $59.68 \%(n=37)$ were in the age group of 21-30 years. (Table-1) Among them 51.61\% $(n=32)$ had far advanced pulmonary lesion on chest X-ray (radiological status, table-2) As mentioned in table-3 the menstrual irregularities in most of the women were secondary amenorrhoea (48.39\%; n=30) However menorrhagia and irregular cycle were two other commonest presentations next to secondary amenorroea observed in $16.13 \%(n=10)$ and $14.52 \%(n=9)$ patients respectively. Dysmenorrhoea was also one of the complain in $6.45 \%(n=4)$ patients. Maximum number of the study population presented with secondary amennorrhoea were in the first year of development of pulmonary tuberculosis. ( 0-6 months: $n=9$ and 712 months: $n=14)$ The women with irregular cycle were also observed within 0-6months ( $n=6)$ and 7-12 months $(n=2)$.

On per vaginal examination the vaginal discharge was observed in $24.19 \%(n=15)$ of patients. Cervical lesion including erosion $(25.81 \% ; \mathrm{n}=16)$ and ulceration $(12.09 \% ; \mathrm{n}=08)$ were also noted. (Table-4) The uterine size was normal in $25.81 \%(n=16)$ and small in $16.13 \%(n=10)$ females. Adnexal mass was also found in $9.68 \%(n=6)$ women. (Table-4)

In our study population, the maximum histological pattern with the proliferative endometrium was observed in $38.71 \%(n=24)$ females. The secretory endometrium was seen in $25.81 \%(n=16)$ women. When the endometrial tissues of both histological patterns were subjected for Z-N staining for AFB, all were found to be negative. (Table- 
5) The endometrial reaction is said to be present when there is local infiltration of lymphocytes intermingling with stroma or well defined lymphocytic aggregation or presence of plasma cells. In this study $12.90 \% \quad(n=8)$ cases were taken as chronic endometritis due to endometrial reaction. In histolpathological examinatin of endometrium, the non caseating granuloma and caseation alone were taken as the surest evidence of tubercular endometritis. 4 cases $(6.45 \%)$ showed evidences of tubercular endometritis on histopathological examination and were also found to be AFB positive on Z-N staining of endometrium. All cses of histologically proved endometritis occured within 1 year of developement of symptoms of pulmonary tuberculosis.

Table No. I :- Distribution of cases according to age groups

\begin{tabular}{|c|c|c|}
\hline Age in Years & No. of cases & Percentage \\
\hline $15-20$ & 10 & 27.42 \\
\hline $21-25$ & 17 & 32.26 \\
\hline $26-30$ & 20 & 11.29 \\
\hline $31-35$ & 7 & 8.06 \\
\hline $36-40$ & 5 & 4.84 \\
\hline $41-45$ & 3 & $\mathbf{1 0 0 . 0 0}$ \\
\hline Total & $\mathbf{6 2}$ & \\
\hline
\end{tabular}

Table No 2:- Distribution of cases according to radiological status of lungs in pulmonary tuberculosis

\begin{tabular}{|l|c|c|}
\hline Radiological Status & No. of Cases & Percentage \\
\hline Minimal Lesion & 5 & 8.06 \\
\hline Moderately advanced & 25 & 40.32 \\
\hline Far Advanced Total & 32 & 51.61 \\
\hline \multicolumn{2}{c|}{ 62 } & $\mathbf{1 0 0 . 0 0}$ \\
\hline
\end{tabular}

Table No. 3:- Menstrual pattern and its relation to duration of pulmonary tuberculosis

\begin{tabular}{|c|c|c|c|c|c|c|c|}
\hline \multirow[t]{2}{*}{ Menstrual pattern } & \multirow[t]{2}{*}{$\begin{array}{l}\text { No. of } \\
\text { cases }\end{array}$} & \multirow[t]{2}{*}{ Percentage } & \multicolumn{5}{|c|}{$\begin{array}{c}\text { Duration of pulmonary tuberculosis } \\
\text { (In months) }\end{array}$} \\
\hline & & & $0-6$ & $7-12$ & 13-18 & 19-24 & $24+$ \\
\hline Normal Cycle & 5 & 8.06 & 1 & - & 3 & 1 & - \\
\hline Primary amenorrhea & - & 0 & - & - & - & - & - \\
\hline Secondary amenorrhea & 30 & 48.39 & 9 & 14 & 2 & 1 & 4 \\
\hline Oligomenorrhea & 4 & 6.45 & 1 & 3 & - & - & - \\
\hline Menorrhagia & 10 & 16.13 & - & 5 & 1 & 2 & 2 \\
\hline Irregular cycle & 9 & 14.52 & 6 & 2 & 1 & - & - \\
\hline Dysmenorrhea & 4 & 6.45 & 3 & 1 & - & - & - \\
\hline Total & 62 & 100.00 & 20 & 25 & 7 & 4 & 6 \\
\hline
\end{tabular}

Table No. 4:- Results of vaginal examination of all cases studied

\begin{tabular}{|l|l|l|}
\hline \multicolumn{1}{|c|}{ Results } & \multicolumn{1}{|c|}{ No. of cases } & \multicolumn{1}{|c|}{ Percentage } \\
\hline (1)Vaginal discharge & 15 & 24.19 \\
\hline $\begin{array}{l}\text { (2)Cervical lesion } \\
\text { (a) Erosion }\end{array}$ & 16 & \\
(b) Ulceration & 8 & 25.81 \\
\hline (3)Uterine size of Length & & 12.09 \\
(a) Normal & 16 & \\
(b) Small & 10 & 25.81 \\
\hline (4)Adnexal mass & 6 & 16.13 \\
\hline
\end{tabular}

Table No .5:- Histopathological pattern and z-n staining of endometrium in cases of pulmonary tuberculosis

\begin{tabular}{|l|c|c|c|c|}
\hline \multicolumn{1}{|c|}{ Histological pattern } & No. of cases & Percentage & \multicolumn{2}{|c|}{ Z-N staining status } \\
\cline { 3 - 5 } & & & +ve & - \\
\hline Secretory & 16 & 25.81 & 16 \\
\hline Proliferative & 24 & 38.71 & - & 24 \\
\hline
\end{tabular}




\begin{tabular}{|c|c|c|c|c|}
\hline Tubercular endometritis & 4 & 6.45 & 4 & - \\
\hline Chronic endometritis & 8 & 12.90 & - & 8 \\
\hline No endometrium & 10 & 16.13 & - & 10 \\
\hline Total & $\mathbf{6 2}$ & $\mathbf{1 0 0 . 0 0}$ & $\mathbf{4}$ & $\mathbf{5 8}$ \\
\hline
\end{tabular}

\section{Discussion:-}

Pulmonary tuberculosis is a communicable disease usually involves the lungs but may involve the other organs particularly genital organs though rare. Genital TB occurs mostly secondary to pulmonary tuberculosis, commonly spreads by the haematogenous route in a manner similar to spread to other extra-pulmonary sites like urinary tract, bones and joints etc. The fallopian tubes are affected in almost $100 \%$ of the cases of genital tuberculosis followed by the endometrium in 50\%, ovaries in $20 \%$, cervix in 5\% cases. Also vagina and vulva are other commonly involved sites. (Weerakaiet et al, 1999) Endometrial tuberculosis though uncommon, still an important clinical entity in developing countries like India. (Hassimoto A et al, 1994, Haider P et al, 1992, Hunter B et al, 1998, Jhon M et al, 1999)

In the present study, it was observed that 59.68\% patients of pulmonary tuberculosis associated with gynaecological problems were in the age group of 21-30 years. Our study observations corroborate with that of Nawaz et al, 2005 who reported the TB endometritis is more common in the reproductive age group mostly between $20-45$ years.

In this study sample, the commonest menstrual disorder was observed to be secondary amenorrhoea (48.39\%) and the patients had it in the first year of development of pulmonary tuberculosis. Menorrhagia was another symptom which was found in patients with far advanced lesion of lungs in pulmonary tuberculosis (16.13\%) and dysmenorrhoea in $6.45 \%$ of cases. In an earlier study, Samal et al. reported that the patients of genital TB had oligomenorrhoea in $54 \%$, menorrhagia in $19.0 \%$, and amenorrhea in $14.3 \%$ of cases.

Histopathological observations of endometrial tissue in our study revealed proliferative endometrium in $38.71 \%$ cases but when these endometrium were subjected to Z-N staining for AFB, came out to be negative. The endometrial tissue obtained in secretory phase ( $25.81 \%$ of cases) and chronic endometritis ( $12.90 \%$ cases ) were also negative for AFB in Z-N staining. Tubercular endometritis was seen in $6.45 \%$ of cases and all these endometrium obtained in these females were bacteriologically positive for AFB in Z-N staining. But in the study of Butt et al., 2003. microscopic examination by Z- N staining revealed absence of AFB in all endometrial tissues even in a larger sample size.

\section{Conclusion:-}

As endometrial tuberculosis is one of the causes of infertility and other gynecological complications, the bacteriological examination of endometrium with Z-N staining for AFB should be done along with histopathological evaluation for early diagnosis. As tuberculosis is amenable to modern drug treatment, the importance of early diagnosis becomes more relevant.

\section{Acknowledgement:-}

We acknowledge the cooperation of all the patients who participated in this study, services of department of Pulmnary medicine, Pharmaclogy, Obstetrics and Gynecology and Pathology for helping in the preparation of this manuscript.

\section{References:-}

1. Angus BJ Yates M , Conion C Byren I (2001) Cutaneous tuberculosis of penis and sexual transmission of tuberculosis confirmed by molecular typing. Cli Infect Dis, 33(11): E132-4

2. A. Kriplani , A. Bahadur, V. Kulshrestha, N. Agarwal, S. Singh, U.B. Singh (2017) Role of anti-tubercular treatment for positive endometrial aspirate DNA-PCR reproductive outcome in infertile patients in Indian setting - A randomized trial. IJTB, 6 4: $33-39$

3. Butt, T., Ahmad, R.N., Kazmi, S.U., Raja, K.A., Mahmood, A. (2003). An Update on the diagnosis of Tuberculosis. J. Coll. Physicians. Surg. Pak.,13, 728- 34.

4. Haider P, Jafarey SN. (1992): A histopathological study of endometrial tuberculosis and infertility. J Pak Med Assoc, 42: 269-271 
5. Hashimotos A Koga H, Kohno S., Miyazaki Y, Taira K, Tomono K et al, (1994) : A case of endometrial tuberculosis diagnosed by polymerase chain reaction. Kekaku. 69: 27-30.

6. Hunter B, Macarthy A (1998): Churchills Mastery of Medicine: Obstetrics and Gynecology, Edinburg: Churchill- Livingstone: $307-317$

7. John M, Kukkady Z (1999): Genital tuberculosis and infertility. Int J Of Gynecol Obstet, 64: 193-194

8. Khan Nawaz Frequency of endometrial tuberculosis: A histopathological study of endometrial specimens. JPMI 2005; 19(1): 97-100.

9. Kemal Güngördük, Volkan Ulker, Ahmet Sahbaz, Cemal Ark, and Alı Ismet Tekırdag (2007) Postmenopausal Tuberculosis Endometritis. Infectious Diseases in Obstetrics and Gynecology Volume 2007, Article ID 27028, Published online

10. Namaver, Jahromib,Prasanezha M E, Ghane-Shirazir. Female Genital tuberculosis and infertility. Int J Gynaecol. Obstet 2001; 75(3: 269-72)

11. National strategic plan (2012-17) for TuberculosisDirectorate of Health services, Central TB division, Ministry of Health \& Family Welfare (MoHFW), Government of India, New Delhi, www.TBcindia.

12. Samal S, Gupta U, Agarwal P. (2000) Menstrual disorder in genital tuberculosis. J Indian Med Assoc;98:126-9

13. Talib VH, Pandey J, Khurana SK. (1993): Tuberculosis: an epidemic in the making. Indian J Pathol Microbiol, 36:339-340.

14. Tripathy SN, Tripathy SN. (2002 ):Infertility and pregnancy outcome in female genital tuberculosis. Int J Gynecol Obstet., 76:159-163.

15. Kajal B Punyashetty (2012) Tuberculous endometritis: A worrying recrudescence for infertility. Int J Biol Med Res, 3(2): 1708-171

16. V.K.Arora, K.K.Chopra (2017): India's approach to the standards of TB care. IJTB, $64: 1-4$

17. Weerakiet S.Rojanasakul A, Rochana Wutan M (1999): Female genital tuberculosis : clinical features and trend. J Med assoc Yhai, 82(1): 27-32. 